\title{
Minimally Invasive Surgery vs. Open Surgery for Infectious Spondylodiscitis: A Systematic Review and Meta-Analysis
}

\author{
Ida Bagus Gede Arimbawa, I Gusti Lanang Ngurah Agung Artha Wiguna, Sherly Desnita Savio \\ Department of Orthopaedics and Traumatology, Faculty of Medicine, Udayana University, Sanglah General Hospital, Bali, Indonesia
}

Received: July 2, 2021

Revised: August 14, 2021

Accepted: September 17, 2021

Corresponding Author:

Sherly Desnita Savio, MD

Department of Orthopaedics and

Traumatology, Faculty of Medicine,

Udayana University, Sanglah

General Hospital, Jalan Kesehatan

No. 1, Denpasar, Bali 80114,

Indonesia

Tel: +62-36-1-244330

Fax: +62-36-1-244330

E-mail: sherlydsavio@gmail.com
Objective: Minimally Invasive Spinal (MIS) Procedure has long been used for treating degenerative spinal disorders, however its usage for infectious diseases of the spine has not been described a lot in literatures. Through this meta-analysis, we aim to objectively describe the efficacy of MIS as compared to traditional open surgery (OS) in treating infectious spondylodiscitis. Methods: A systematic search was conducted based on PRISMA guideline to identify relevant studies through PubMed, Google Scholar, and Cochrane database. A total of 4 studies (301 patients) were included, divided into 8 meta-analysis, processed using Review Manager 5.3.

Results: OS requires significantly longer hospital length of stay $\left(p=0.0009, I^{2}=0 \%, M D=-6.64\right)$ and higher blood loss $\left(p<0.00001, l^{2}=40 \%, M D=-264.31\right)$ as well as more postoperative blood transfusion $\left(\mathrm{p}<0.00001, \mathrm{l}^{2}=0 \%, \mathrm{MD}=-1.58\right)$. Moreover, MIS has benefit in significantly shorter operation time $\left(p<0.00001, I^{2}=46 \%, M D=-30.07\right)$ and less complication rate $(p=0.0002$, $I^{2}=38 \%, M D=0.32$ ). However, the two procedures do not differ significantly in terms of neurological improvement, recurrence rate, and mortality rate.

Conclusion: Current systematic review and meta-analysis suggest that MIS offers comparable efficacy as well as less hospital length of stay, blood loss, operation time, and complication rate compared to OS.

Key Words: Meta-analysis, Minimally invasive surgery, Open surgery, Spondylodiscitis

\section{INTRODUCTION}

Infectious spondylitis is estimated to affect 4-24 patients per million per year, with male:female ratio of 1.5:2.1. Contributing to $0.15 \%-5 \%$ of all osteomyelitis cases, until date, the treatment of infectious spondylitis is still very challenging in order to minimalize the mortality and morbidity of these patients [1,2].

Surgical intervention is needed in patients unresponsive to antibiotic treatments, those with spinal instability, neurological deficit, soft tissue abscess involvement, and significant spinal destruction. In order to ensure infection eradication, open sur- gery has been used more commonly. However it has been related to postoperative complications and morbidity, especially in immunocompromised and vulnerable patients [3,4].

As a developing method in spine surgery, Minimally Invasive Spinal (MIS) Procedure has long been used for treating degenerative spinal disorders. However, over the years its usage has been extended for other pathologies. Unfortunately, its usage for infectious diseases of the spine has not been described a lot in literatures. Compared to traditional open surgery, MIS offers less duration of surgery, less muscular trauma, and shorter hospital stay, making it a potential treatment method, especially in

Copyright (C) 2021 Korean Minimally Invasive Spine Surgery Society

This is an Open Access article distributed under the terms of the Creative Commons Attribution Non-Commercial License (http://creativecommons.org/licenses/by-nc/4.0/) which permits unrestricted non-commercial use, distribution, and reproduction in any medium, provided the original work is properly cited. 
high-risk patients with infectious spondylitis [1].

Until now, there has not been any consensus thoroughly describing the difference between MIS and OS as the treatment for infectious spondylitis. Through this meta-analysis, we aim to objectively describe the efficacy of the two procedures in treating this pathology.

\section{MATERIALS AND METHODS}

The study design was a systematic review and meta-analysis of relevant comparative studies. A systematic search was conducted from September 2020 to April 2021 to identify relevant studies through PubMed, Google Scholar, Cochrane, Medline, and EMBASE Database based on PRISMA guidelines (Figure 1). The keywords used were: "Minimally Invasive Spine Surgery" AND “Open Surgery” AND ("Spondylodiscitis" OR "Spine Infection" OR "Spondylitis") AND “Efficacy”.

Though there has been no strict definition of Minimally Invasive Spine Surgery, but McAfee et al. (2010) [5] defined MIS as a surgical technique resulting in less tissue damage, decreased morbidity, and faster functional recovery than traditional open surgery, without differentiation in intended surgical goals, in which several terms are encompassed, such as "mini-open",

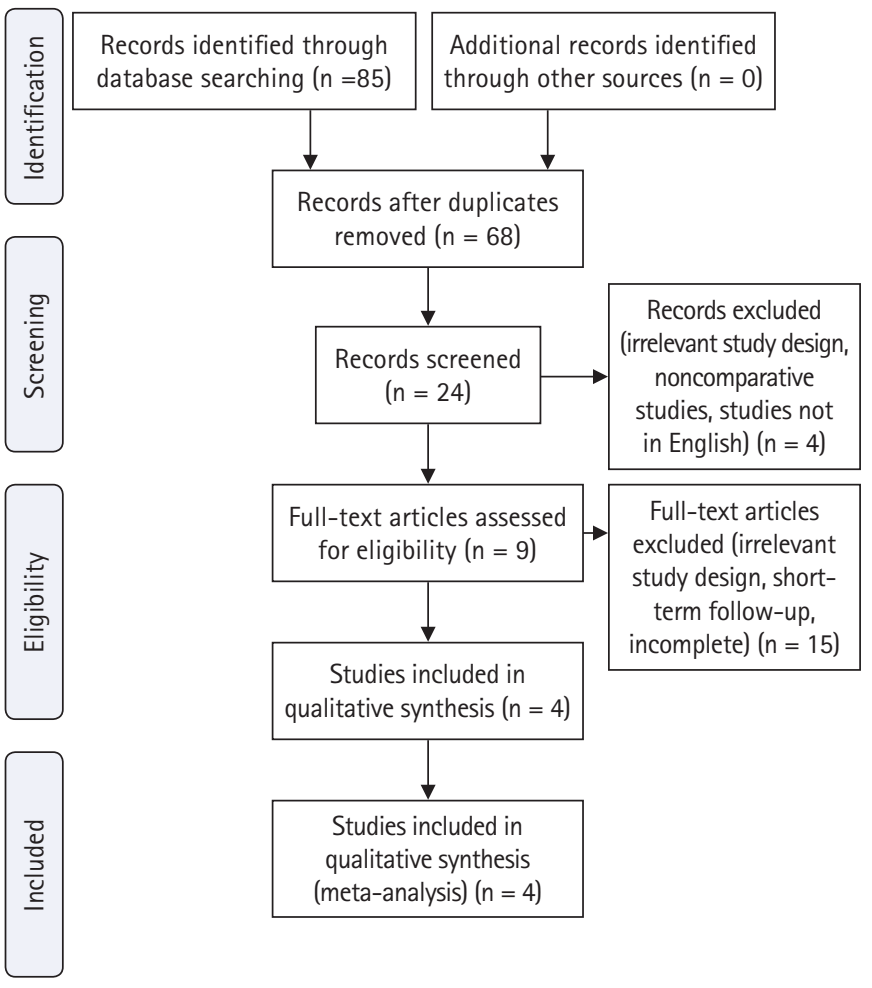

Figure 1. Flow chart showing article selection based on PRISMA guidelines. "tubular", or "percutaneous".

Those studies were then manually scanned and reviewed by all authors according to the following inclusion criteria: (1) minimally invasive spinal surgery and open surgery were interventions under comparison; (2) the population included patients with infectious spondylodiscitis diagnosed through clinical, radiological, and/or laboratory studies, in thoracolumbosacral location; (3) at least one of the following outcomes was reported: hospital length of stay, blood loss, blood transfusion, operation time, neurological outcome, pain, complication rate, recurrence rate, mortality rate, (4) the study was published in English, and (5) applied a randomized controlled trial (RCT) or cohort study design. The exclusion criteria were: (1) less than 2 years of follow up, (2) trauma, degenerative, and oncological pathology, (3) animal studies, (4) case reports or series, review articles, and noncomparative studies are also excluded. Table 1 presents the inclusion and exclusion criteria according to the PICO method (Population, Intervention, Comparison, and Outcome).

Of all potential studies, critical appraisal was performed to assess the eligibility of those studies using a scoring system adapted from Joanna Briggs Institute (JBI), comprising 10 aspects from the view of population, exposures, confounding factors, outcome, follow-up, and statistical analysis. From each included study, data related to patient and study characteristics (e.g. age, sex, level of pathology, causative organisms) and outcomes were extracted and aggregated. Continuous variables hospital stay, blood loss, blood transfusion, operation time were compared in terms of weighted mean difference (WMD). Dichotomous variables - neurological improvements, complication rate, recurrence rate, mortality rate - were assessed in terms of odds ratio (OR) and 95\% confidence intervals (CI). Calculations were performed using Review Manager (RevMan) software (Version 5.3. Copenhagen: The Nordic Cochrane Centre, the Cochrane Collaboration, 2014). A fixed-effect model was used when heterogeneity $\left(\mathrm{I}^{2}\right)$ was $<50 \%$, whereas a random-effect model was used when it was $>50 \%$.

\section{RESULTS}

A total of four studies (301 patients) were included in the meta-analysis. All studies were of Level III evidence with cohort retrospective study design (Table 2). Critical appraisal of all studies based on the Joanna Briggs Institute Scoring System showed that none failed to meet more than four validity criteria (Figure 2).

The sample size for MIS was 155 patients, while for OS was 
Table 1. PICO table describing inclusion and exclusion criteria

\begin{tabular}{|c|c|c|}
\hline Study component & Inclusion & Exclusion \\
\hline \multirow[t]{2}{*}{ Population } & $\begin{array}{l}\text { - Infectious spondylodiscitis diagnosed through clinical, } \\
\text { radiological, and/or laboratory studies }\end{array}$ & - Less than 2 years of follow up \\
\hline & - Thoracolumbosacral location & - Trauma, degenerative, and oncological pathology \\
\hline Intervention and Comparison & $\begin{array}{l}\text { - Minimally Invasive Spine (MIS) Surgery (with and without in- } \\
\text { strumentation) and Open Surgery (OS) }\end{array}$ & - All other treatments \\
\hline & - Blood loss & \\
\hline & Blood transfusion & \\
\hline & Operation Time & \\
\hline & - Neurological Outcome & \\
\hline \multirow[t]{3}{*}{ Publication } & - Primary research published in English in a peer-reviewed journal & - Abstracts, editorials, letters \\
\hline & & $\begin{array}{l}\text { - Duplicate publications of the same study/cohort that } \\
\text { do not report on different outcomes }\end{array}$ \\
\hline & & - Conference presentations or proceedings \\
\hline \multirow[t]{2}{*}{ Design } & - Randomized controlled trials & - Case reports or series \\
\hline & - Cohort studies & - Review articles \\
\hline
\end{tabular}

PICO: population, intervention, comparison, and outcome.

Table 2. Studies included in the analysis

\begin{tabular}{lllll}
\hline No. & \multicolumn{1}{c}{ Reference } & \multicolumn{1}{c}{ Journal } & Study design & Level of evidence \\
\hline 1. & Lee et al. (2014) [6] & The Spine Journal & Cohort Retrospective & Level III \\
2. & Lin et al. (2014) [7] & BMC Musculoskeletal Disorders & Cohort Retrospective & Level III \\
3. & Viezens et al. (2017) [1] & World Neurosurgery & Cohort Retrospective & Level III \\
4. & Fu et al. (2019) [4] & Journal of Clinical Medicine & Cohort Retrospective & Level III \\
\hline
\end{tabular}

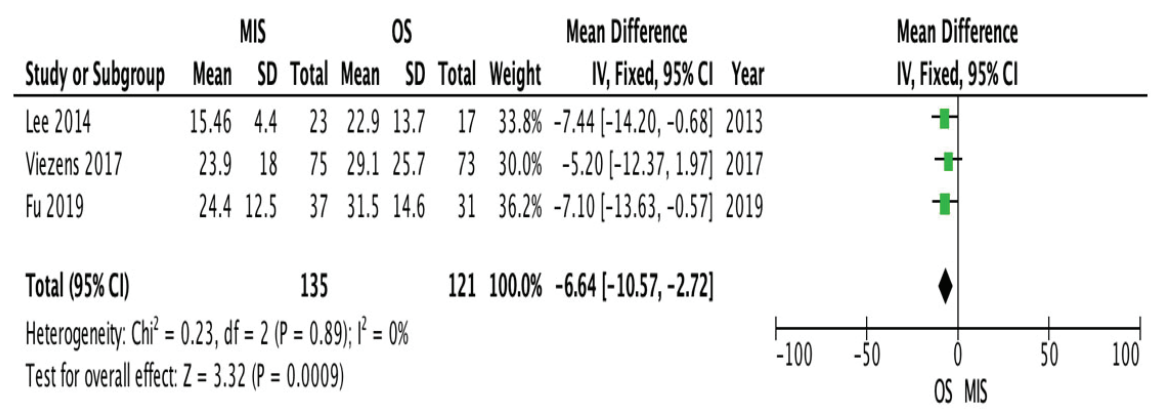

Figure 2. Forest plot for hospital stay.

146 patients. In both groups, biopsy, decompression, and fusion were performed. The sample age ranges from the mean of 56.5-65.8 years old. Males were more commonly affected than females, in both MIS group (F:M=61:94) and OS group ( $F: M=56: 90)$. Lumbar (L) was the most commonly affected region in MIS group (T:TL:L:LS=33:8:103:11) as well as OS group (T:TL:L:LS:S=34:3:100:8:1), followed by thoracal (T) region, lumbosacral (LS), thoracolumbar (TL), and sacral (S) region (Table 3). Pyogenic agent is a more common cause of spondylitis, with $\mathrm{S}$. aureus as the most commonly found organism (MIS:OS=31:38), followed by S. epidermidis (MIS:OS=19:21). No pathogen growth was found in 24 cases in MIS and 22 cases in OS group (Table 4).

OS requires significantly longer hospital length of stay 


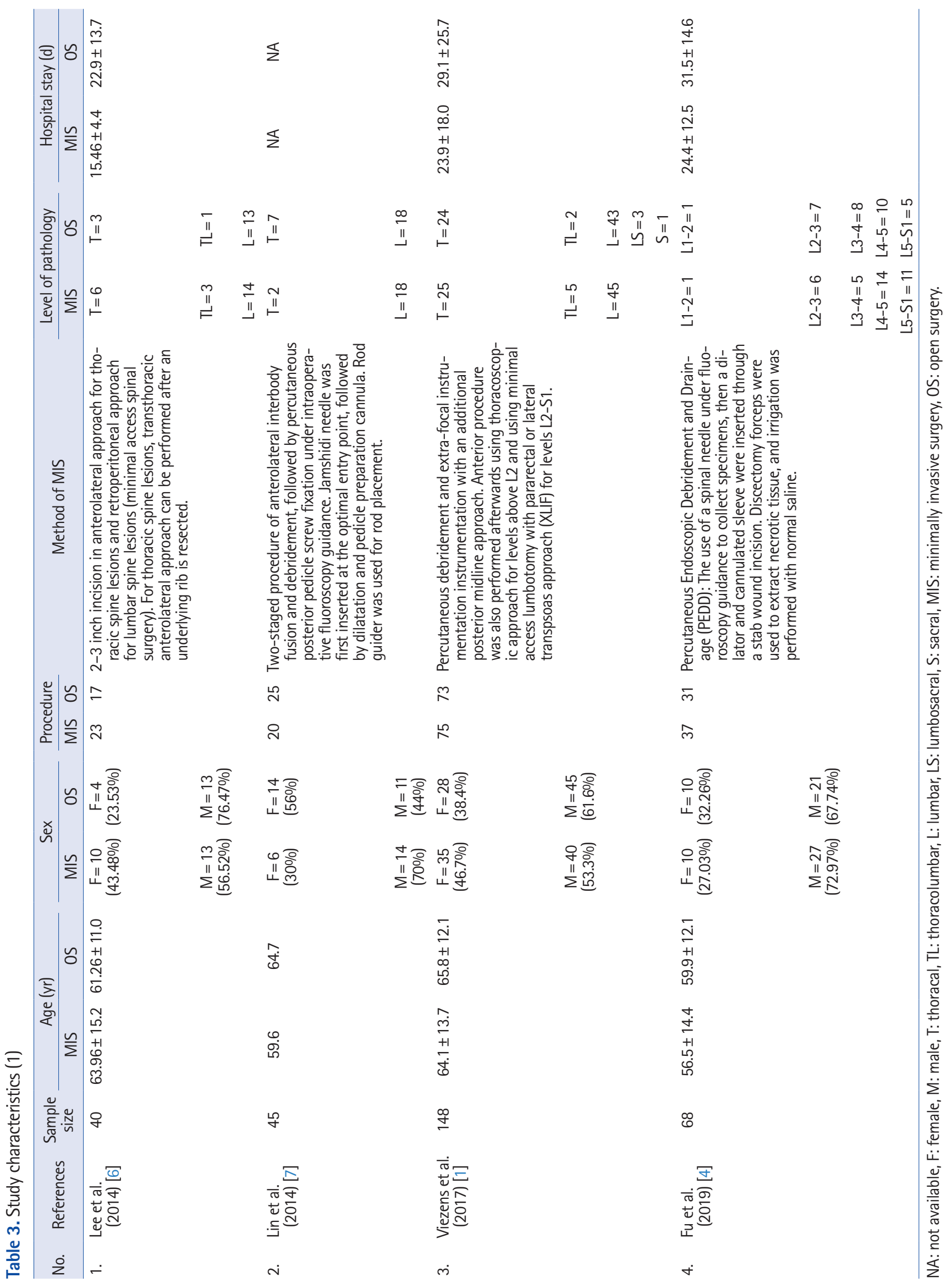




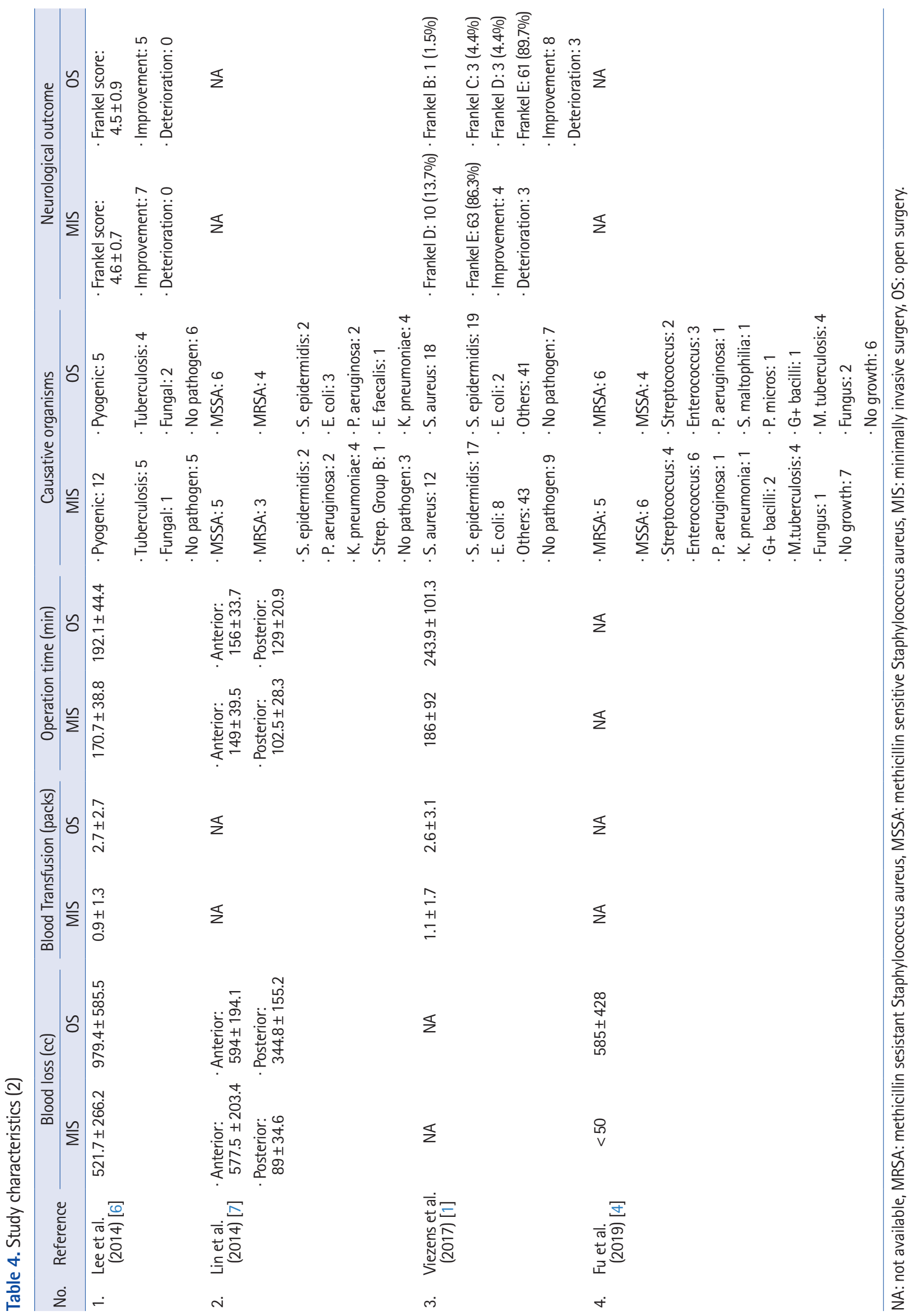


( $\mathrm{p}=0.0009, \mathrm{I}^{2}=0 \%, \mathrm{MD}=-6.64$, Figure 3$)$ and higher blood loss $\left(\mathrm{p}<0.00001, \mathrm{I}^{2}=40 \%, \mathrm{MD}=-264.31\right.$, Figure 4$)$ as well as more postoperative blood transfusion $\left(\mathrm{p}<0.00001, \mathrm{I}^{2}=0 \%, \mathrm{MD}=-1.58\right.$, Figure 5). Moreover, MIS has benefit in significantly shorter operation time $\left(\mathrm{p}<0.00001, \mathrm{I}^{2}=46 \%, \mathrm{MD}=-30.07\right.$, Figure 6$)$ and less complication rate $\left(\mathrm{p}=0.0002, \mathrm{I}^{2}=38 \%, \mathrm{MD}=0.32\right.$, Figure 7$)$. Some complications found are wound dehiscence, asymptomatic loosening, and transient paresthesia (Table 3). However, the two

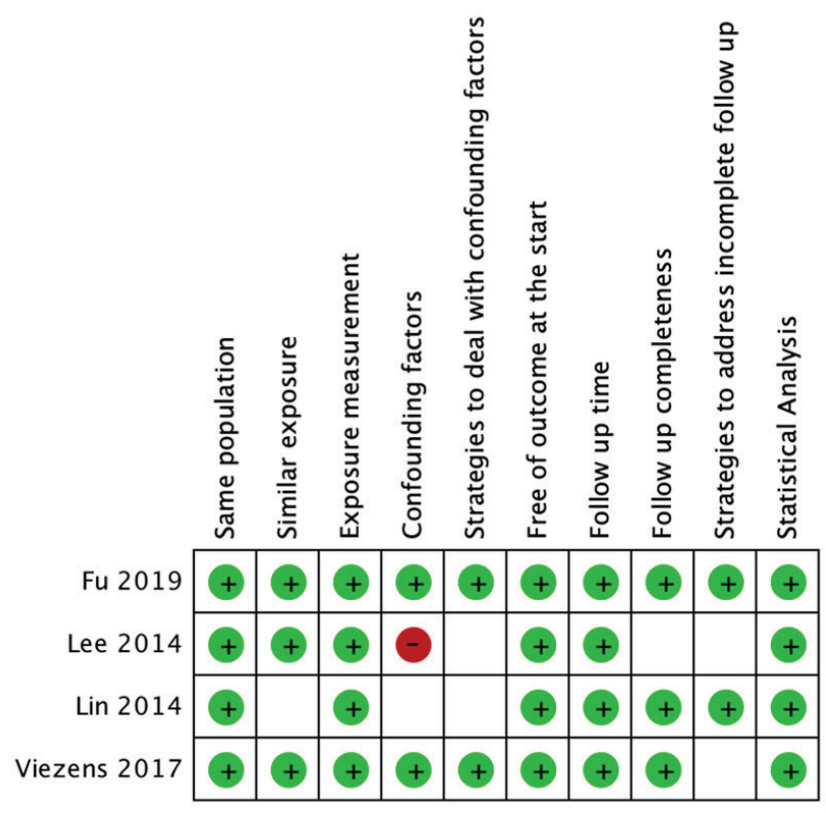

Figure 3. Critical appraisal of all studies included. procedures do not differ significantly in terms of neurological improvement $\left(\mathrm{p}=0.37, \mathrm{I}^{2}=0 \%, \mathrm{MD}=0.66\right.$, Figure 8$)$, recurrence rate $(\mathrm{p}=0.02, \mathrm{MD}=0.13$, Figure 9$)$, and mortality rate $(\mathrm{p}=0.28$, $\mathrm{I}^{2}=0 \%, \mathrm{MD}=0.51$, Figure 10). Postoperative pain after 7 days differs significantly between the two group (MIS:OS=2.8:3.5, $\mathrm{p}=0.03$ ). Follow-up period ranges from 2-9 years (Table 5).

In terms of infection control, some different parameters were taken into account by each author. A study by Lee et al. (2014) [6] measured it from the amount of recurrent infection and death from sepsis, while Lin et al. (2014) [7] used recurrent infection, intraoperative complications (e.g. wound infection, screw loosening), and recurrent fever with elevated infection markers as parameters. Viezens et al. (2017) [1] and Fu et al. (2019) [4] used wound complications needing repeated debridement and screw loosening as signs of poor infection control. From our systematic review, the infection control exhibited by MIS seems to be comparable, if not better, than the OS.

\section{DISCUSSION}

Though nonoperative treatment was effective in $90 \%$ of uncomplicated cases, surgical intervention is needed in those who failed conservative therapy, or those with neurological impairments [4]. As a developing field in spine surgery, percutaneous endoscopic approach has been used more and more over the years, for the treatment of degenerative spine diseases as well as infectious spondylitis, especially for high-risk patients, elderly, and critical or immunocompromised patients $[4,5]$.

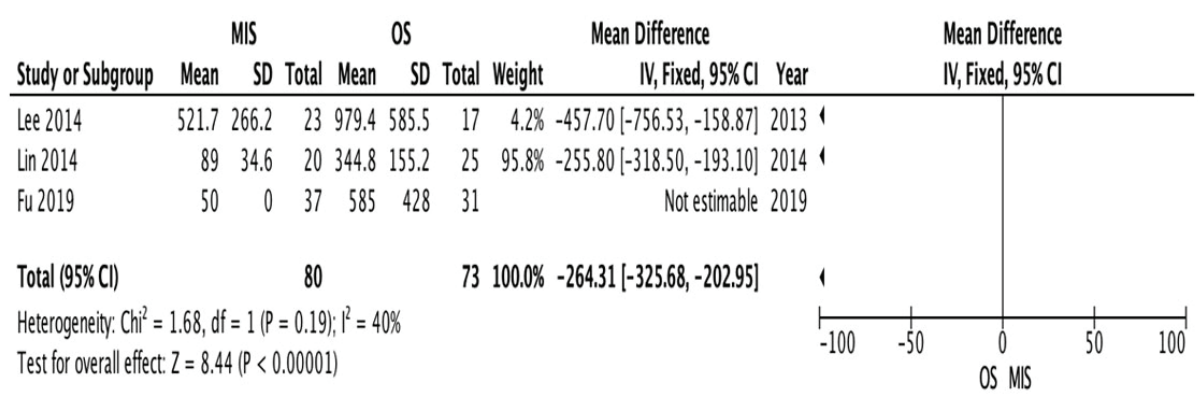



Figure 4. Forest plot for blood loss.

Figure 5. Forest plot for blood transfusion. 


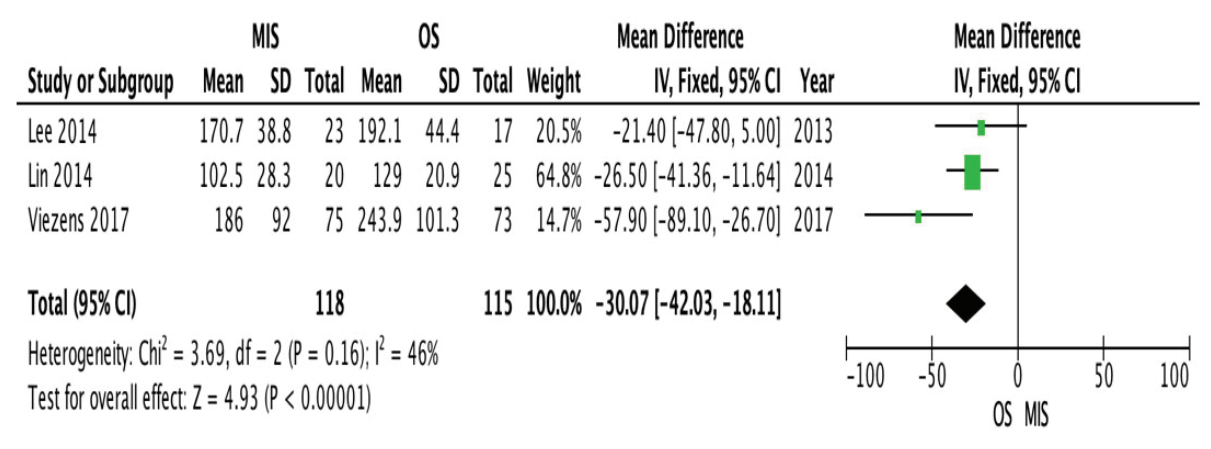

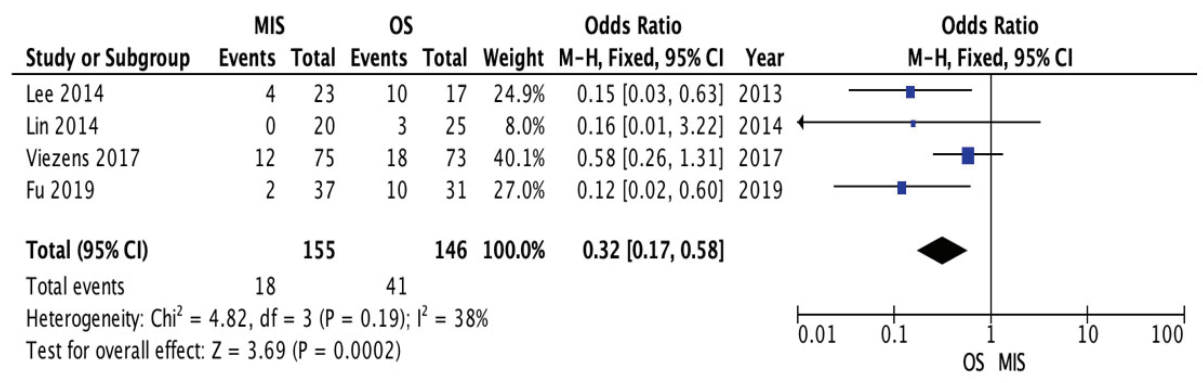

\section{MIS OS Odds Ratio Odds Ratio}

Study or Subgroup Events Total Events Total Weight $\mathrm{M}-\mathrm{H}, \mathrm{Fixed}, 95 \% \mathrm{Cl}$ Year

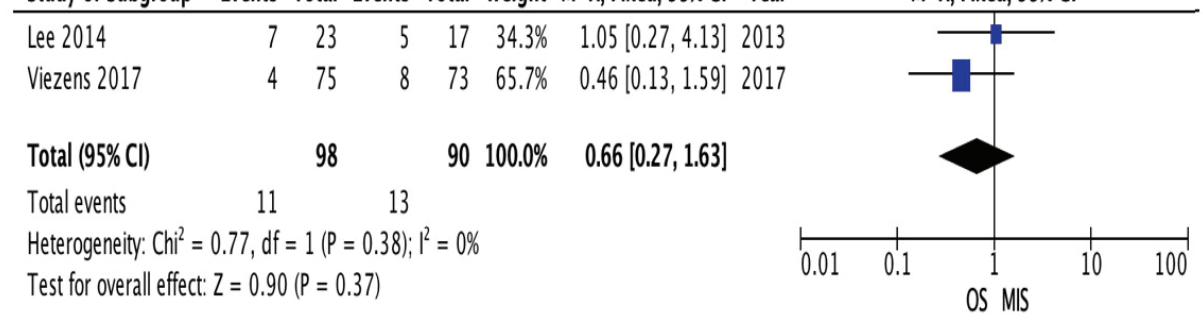

\begin{tabular}{|c|c|c|c|c|c|c|c|c|}
\hline Study or Subgroup & $\begin{array}{l}\text { MIS } \\
\text { Events }\end{array}$ & & $\begin{array}{r}\text { OS } \\
\text { Events }\end{array}$ & & $\begin{array}{l}\text { Odds Ratio } \\
\text { M-H, Fixed, 95\% Cl }\end{array}$ & Year & $\begin{array}{c}\text { Odds Ratio } \\
\text { M-H, Fixed, } 95 \% \mathrm{Cl}\end{array}$ & \\
\hline Lee 2014 & 0 & 23 & 2 & $17 \quad 100.0 \%$ & $0.13[0.01,2.94]$ & 2013 & & \\
\hline Lin 2014 & 0 & 20 & 0 & 25 & Not estimable & 2014 & & \\
\hline Total $(95 \% \mathrm{Cl})$ & & 43 & & $42 \quad 100.0 \%$ & $0.13[0.01,2.94]$ & & & \\
\hline Total events & 0 & & 2 & & & & & \\
\hline \multicolumn{7}{|c|}{$\begin{array}{l}\text { Heterogeneity: Not applicable } \\
\text { Test for overall effect: } Z=1.28(P=0.20)\end{array}$} & $\begin{array}{c}1 \\
\text { OS MIS }\end{array}$ & 10 \\
\hline
\end{tabular}

\section{MIS OS Odds Ratio Odds Ratio}

Study or Subgroup Events Total Events Total Weight $\mathrm{M}-\mathrm{H}, \mathrm{Fixed}, 95 \% \mathrm{Cl}$ Year $\quad \mathrm{M}-\mathrm{H}, \mathrm{Fixed}, 95 \% \mathrm{Cl}$

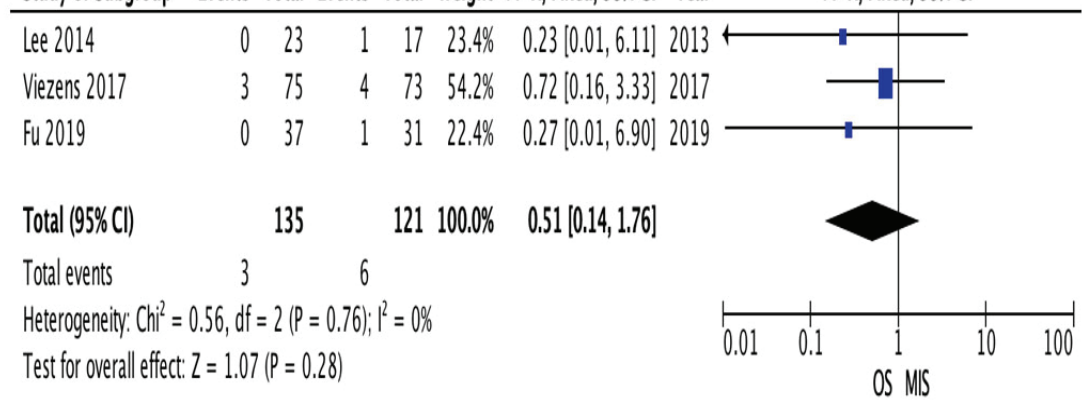

Figure 6. Forest plot for operation time.

Figure 7. Forest plot for complication rate.

Figure 8. Forest plot for neurological improvement.

Figure 9. Forest plot for recurrence rate.

Figure 10. Forest plot for mortality rate. 


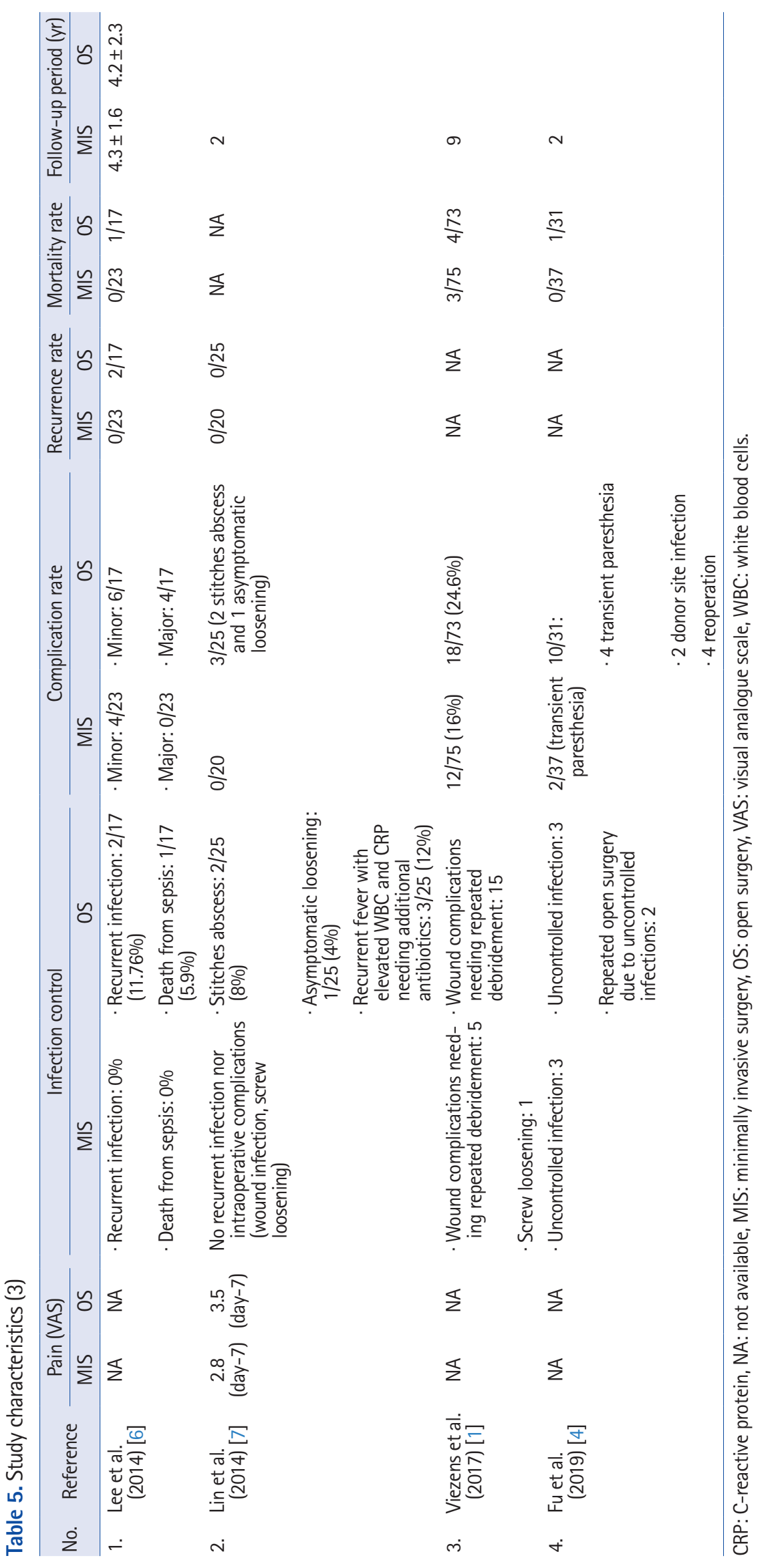


The techniques for performing Minimally Invasive Debridement in infectious spondylitis varies in literatures. Fu et al. (j. Discectomy forceps were used to extract necrotic tissue, and irrigation was performed with normal saline. A drainage tube was inserted afterwards for several days postoperatively [4]. Another study by Viezens et al. (2017) [1] described percutaneous debridement and instrumentation with an additional posterior midline approach to achieve adequate laminotomy or laminectomy with abscess drainage and disc resection. Anterior procedure was also performed afterwards using thoracoscopic approach for levels above L2 and using minimal access lumbotomy with pararectal or lateral transpsoas approach (XLIF) for levels L2-S1 [1]. Lin et al. (2014) [7] in their study utilized two-staged procedure of anterolateral interbody fusion and debridement, followed by percutaneous posterior pedicle screw fixation under intraoperative fluoroscopy guidance. Jamshidi needle was first inserted at the optimal entry point, followed by dilatation and pedicle preparation cannula. Rod guider was used for rod placement [8]. On the other hand, a study by Lee et al. (2014) [6] described slightly longer incision of 2-3 inch in anterolateral approach for thoracic spine lesions and retroperitoneal approach for lumbar spine lesions. Chest tube or Hemovac drain was installed postoperatively [7].

Even though minimally invasive percutaneous approach procedure resulted in comparable fusion rate and good early functional recovery, MIS also generally has lower positive culture rate $(58 \%-90 \%)$. This is possibly caused by the advantage of OS in obtaining direct access to the infected area for debridement and pus collection for further microbiology examination [6,9]. However, a study by Mao et al. (2019) [10] stated that despite its minimally invasive approach, PED can completely eliminate infected tissue, enhancing local blood flow, supporting antibiotic infiltration, and resulting in good clinical result.

In a study by Yang et al. (2007) [11], percutaneous spine procedure via endoscope was proven to be satisfactory, however prolonged pain and pre-existed anterior vertebral body damage caused postoperative immobilization for a long time, which could potentially lead to numerous complications. Thorough debridement and antibiotic therapy aid to eradicate the infection and control the progression of bony destruction, whereas the addition of instrumentation procedure is beneficial for early mobilization and reduction of kyphotic progression [3]. Technically, a study by Wu et al. (2020) [12] compares unilateral and bilateral percutaneous endoscopic debridement (PED) for lumbar spinal tuberculosis in 20 patients, concluded that unilateral PED is better than bilateral PED due to its shorter du- ration of surgery and comparable postoperative inflammatory markers, VAS, ODI, and complication rate.

Through the result of our study, MIS is proven to have significantly shorter operation time compared to OS, supported by the fact that MIS needs shorter duration for paraspinal muscle preparation and wound closure by the end of surgery. On the other hand, fluoroscopy time is longer in MIS, due to the increase of difficulty in visualizing spinal anatomical structure, especially when instrumentation is being performed. This counts as a disadvantage of MIS, as it prolongs the radiation exposure to the staff in operation room. However, these aspects are highly influenced by the learning curve and familiarity of the operator towards minimally invasive spine procedures [1].

In terms of complication, MIS displays lower rate compared to OS. Some complications mentioned for MIS are transient paresthesia or numbness, local infection, local kyphosis, and reoperation $[7,12,13]$. On the other hand, traditional open surgery has been associated with complications such as significant paraspinal soft tissue denervation, pleural effusion, diaphragm injury, and vascular injury (up to $15 \%$ with related mortality rate of $1 \%$ ) $[7,14]$. To date, there have not been a lot of literatures mentioning surgical-related complications of PED for infectious spondylitis. A study by Fu et al. (2013) [15] stated that PED showed good efficacy as well as diagnostic value with no surgery-related complications in both uncomplicated and complicated infectious spondylodiscitis [16]. However, this matter might require further studies with larger amount of samples to draw more accurate conclusions, considering PED could be related to some neurological complications in the treatment of degenerative disc disease, such as postoperative dysesthesia. Sairyo et al. (2014) [17] in their study stated that the incidence of exiting nerve injury reached up to $8.9 \%$ in transforaminal approach. This is due to the direct injury by a cannula (supported by the fact that the patients were in anesthesia and unaware when the nerve was injured), or due to the prolonged intraoperative compression by cannula causing irritation of dorsal root ganglion (in which the leg dysesthesia typically occurs several days postoperatively) [15]. Other possible contributing factor to neurological problems in PED is the development of epidural or retroperitoneal hematoma, caused by possible injury to adjacent arteries $[17,18]$. Intracranial hypertension was also described in literatures, leading to headache, seizure, even death. This could happen due to the administration of contrast media into thecal sac, combined with dural tear, continuous infusion of fluid and medication. Therefore careful monitoring of perioperative symptoms and vital signs should always be per- 
formed, particularly the typical signs of seizures such as neck pain and increased intracranial or epidural pressure [15,1719]. Some measures can be performed in order to minimalize these possible complications, such as using local anesthesia in conscious patients, careful monitoring of working channel position, and practicing the familiarity of local anatomy as viewed through endoscope $[14,19,20]$. Regardless all the benefits and complications of PED, traditional open surgery should still be considered in advanced stage infectious spondylitis, multilevel pathology, severe spinal instability, presence of abscess, and large bony defects, where further spinal reconstruction will be necessary [4].

To our knowledge, this is the first meta-analysis to objectively compare the efficacy between MIS and OS for infectious spondylitis. Another meta-analysis by Mao et al. (2019) [10] summarized the efficacy of percutaneous endoscopic debridement for spinal infection, however it was noncomparative study using one-arm analysis. This study has several limitations: (1) All four studies included into the analysis were of Level III evidence; (2) Due to the limited number of available studies, it was decided to include debridement procedure with and without instrumentation. Second-step procedure was also included into the analysis. This may bias our results, however we have ensured that the difference of baseline characteristics was not significant between control and intervention groups; (3) Incision length of the minimally invasive procedure was not exactly the same in all literatures. However, in all studies, the MIS procedures were all less invasive compared to traditional OS. This study also has several advantages: (1) To our knowledge, it is the first meta-analysis to objectively compare MIS and OS for Infectious Spondylitis; (2) The heterogeneity of all eight forest plots were $<50 \%$, reflecting the representativeness of studies included into the analysis (3) Outcomes were thoroughly assessed, in terms of several outcome measures, aiming to show the different dimensions of infectious spondylitis therapy. It is hoped that this study could serve as an influential bridge to future research with larger sample sizes, as well as a clinical guideline for choosing surgical therapeutic approach for patients with infectious spondylitis.

\section{CONCLUSION}

Current systematic review and meta-analysis suggest that MIS offers comparable efficacy as well as less hospital length of stay, blood loss, operation time, and complication rate compared to OS.

\section{CONFLICT OF INTEREST}

No potential conflict of interest relevant to this article.

\section{REFERENCES}

1. Viezens L, Schaefer C, Helmers R, Vettorazzi E, Schroeder M, Hansen-Algenstaedt N. Spontaneous pyogenic spondylodiscitis in the thoracic or lumbar spine: a retrospective cohort study comparing the safety and efficacy of minimally invasive and open surgery over a nine-year period. World Neurosurg 2017;102:18-27.

2. Mavrogenis AF, Megaloikonomos PD, Igoumenou VG, Panagopoulos GN, Giannitsioti E, Papadopoulos A, et al. Spondylodiscitis revisited. EFORT Open Rev 2017;2:447-461.

3. Duan K, Qin Y, Ye J, Zhang W, Hu X, Zhou J, et al. Percutaneous endoscopic debridement with percutaneous pedicle screw fixation for lumbar pyogenic spondylodiscitis: a preliminary study. Int Orthop 2020;44:495-502.

4. Fu TS, Wang YC, Lin TY, Chang CW, Wong CB, Su JY. Comparison of percutaneous endoscopic surgery and traditional anterior open surgery for treating lumbar infectious spondylitis. J Clin Med 2019;8:1356.

5. McAfee PC, Phillips FM, Andersson G, Buvenenadran A, Kim CW, Lauryssen C, et al. Minimally invasive spine surgery. Spine (Phila Pa 1976) 2010;35:S271-S273.

6. Lee CY, Huang TJ, Li YY, Cheng CC, Wu MH. Comparison of minimal access and traditional anterior spinal surgery in managing infectious spondylitis: a minimum 2-year follow-up. Spine J 2014;14:1099-1105.

7. Lin TY, Tsai TT, Lu ML, Niu CC, Hsieh MK, Fu TS, et al. Comparison of two-stage open versus percutaneous pedicle screw fixation in treating pyogenic spondylodiscitis. BMC Musculoskelet Disord 2014;15:443.

8. Choi EJ, Kim SY, Kim HG, Shon HS, Kim TK, Kim KH. Percutaneous endoscopic debridement and drainage with four different approach methods for the treatment of spinal infection. Pain Physician 2017;20:E933-E940.

9. Deininger MH, Unfried MI, Vougioukas VI, Hubbe U. Minimally invasive dorsal percutaneous spondylodesis for the treatment of adult pyogenic spondylodiscitis. Acta Neurochir (Wien) 2009;151:1451-1457.

10. Mao Y, Li Y, Cui debridement, drainage for spinal X. Percutaneous endoscopic debridement and drainage for spinal infection: systemic review and meta-analysis. Pain Physician 2019;22:323-330.

11. Yang SC, Fu TS, Chen LH, Niu CC, Lai PL, Chen WJ. Percu- 
taneous endoscopic discectomy and drainage for infectious spondylitis. Int Orthop 2007;31:367-373.

12. Wu D, Sun J, Fan W, Yuan F. Unilateral or bilateral percutaneous endoscopic debridement and lavage treatment for lumbar spinal tuberculosis. World Neurosurg 2020;140:e73-e80.

13. Kandwal P, Garg B, Upendra B, Chowdhury B, Jayaswal A. Outcome of minimally invasive surgery in the management of tuberculous spondylitis. Indian J Orthop 2012;46:159-164.

14. Hsu LC, Tseng TM, Yang SC, Chen HS, Yen CY, Tu YK. Bilateral portal percutaneous endoscopic debridement and lavage for lumbar pyogenic spondylitis. Orthopedics 2015;38:e856e863.

15. Fu TS, Chen LH, Chen WJ. Minimally invasive percutaneous endoscopic discectomy and drainage for infectious spondylodiscitis. Biomed J 2013;36:168-174.

16. Yang J, Liu C, Hai Y, Yin P, Zhou L, Zhang Y, et al. Percutaneous endoscopic transforaminal lumbar interbody fusion for the treatment of lumbar spinal stenosis: preliminary report of seven cases with 12-month follow-up. Biomed Res Int 2019;2019:3091459.

17. Sairyo K, Matsuura T, Higashino K, Sakai T, Takata Y, Goda
$\mathrm{Y}$, et al. Surgery related complications in percutaneous endoscopic lumbar discectomy under local anesthesia. J Med Invest 2014;61:264-269.

18. Pan M, Li Q, Li S, Mao H, Meng B, Zhou F, et al. Percutaneous endoscopic lumbar discectomy: indications and complications. Pain Physician 2020;23:49-56.

19. Kim HS, Sharma SB, Wu PH, Raorane HD, Adsul NM, Singh $\mathrm{R}$, et al. Complications and limitations of endoscopic spine surgery and percutaneous instrumentation. Indian Spine J 2020;3:78-85.

20. Zhou C, Zhang G, Panchal RR, Ren X, Xiang H, Xuexiao M, et al. Unique complications of percutaneous endoscopic lumbar discectomy and percutaneous endoscopic interlaminar discectomy. Pain Physician 2018;21:E105-E112.

21. Ao S, Zheng W, Wu J, Tang Y, Zhang C, Zhou Y, et al. Comparison of preliminary clinical outcomes between percutaneous endoscopic and minimally invasive transforaminal lumbar interbody fusion for lumbar degenerative diseases in a tertiary hospital: is percutaneous endoscopic procedure superior to MIS-TLIF? A prospective cohort study. Int J Surg 2020;76:136-143. 